\title{
SOCIAL NETWORKING IN SMALL BUSINESS: VALIDATION OF A RESEARCH MODEL
}

\author{
Cesar Ayala, Georgia Southern University, cesar_ayala@georgiasouthern.edu \\ Geoffrey Dick, Georgia Southern University, geoffreydick@georgiasouthern.edu \\ Camille Rogers, Georgia Southern University, cfrogers@georgiasouthern.edu \\ Robert Szymanski, Georgia Southern University, rszymanski@georgiasouthern.edu
}

\begin{abstract}
Information technology has spawned social networking - a phenomenon widely embraced by big business to increase contact with customers, identify new markets and to obtain feedback on products and services. Small businesses, slower to adopt the new technology, risk being left behind. This paper takes a theoretical research framework developed to study how technological fit and viability affect the decision to deploy, and subsequent performance evaluation, and tests it as a research model for adoption of social networking by small business. Extensive use of Structural Equation Modeling using PLS enabled verification of significant components of the model and suggested certain variations for further research.
\end{abstract}

Keywords: Social Networking, Small Business, PLS, Structural Equation Modeling

\section{INTRODUCTION}

Social networks on the Internet have changed the way we work and live. Many of these networks are business oriented and can create business opportunities - perhaps the most notable of these is LinkedIn which concentrates on job placements and business opportunities, however business has taken advantage of Facebook, MySpace, Second Life and other such social networks to promote their institutions, their products their brands, and to obtain feedback.

The Web 2.0 technologies, which include discussion forums, blogs, and wikis, have been used by many companies to achieve varying business objectives. These range from promoting products to increasing market share, developing new markets, training of staff, development of a knowledge base for use by staff and customers, and testing of economic viability. In recent times we have seen most major corporations asking that customers and contacts "friend "them on Facebook - they can be expected to become involved in other social networking tools. In this paper the terms social media and social networking are used interchangeably and refer to interactions among people in which they create, share, and exchange information and ideas using virtual communities.

Some research has been conducted on big business's use of social networking [2, 12, 16, 21]. This study attempts to test the suitability of a research framework for small business, an area of the economy that is in danger of losing market share as big business exploits the available technology, and to some extent utilizes resources differently to small business - think big chain supermarkets using logistics and customer focus to kill the corner store, online book-sellers using e-commerce to threaten the demise of the local bookshop. An essential question that this study aims to address is can social networking help small business?

\section{BACKGROUND}

Burnoff [2] makes the point that the potential benefits of customer relationships, both direct and intimate, that social applications provide a business are too important for them to ignore. The groundswell in social networking (Facebook is claiming over 6 billion "active" members) while not providing a panacea for business deficiencies, does force business to promote customer-centric thinking. A customer focus has long been a strength of small business - now social networking is allowing big business to compete more strongly in this area. Sinclaire [21] suggests that there is an increased use of social media and social networking sites by organizations resulting in various uses from the passive to the active, proactive to reactive, and tactical or strategic uses. Put another way this suggests that business has seen a wide range of possibilities and is looking for ways to exploit them. Larson and 


\section{Issues in Information Systems}

Volume 14, Issue 1, pp.234-243, 2013

Watson develop this further into multiple layers of actions by the firm and by the customer in an attempt to provide a theoretical understanding of what these entities aim to achieve by the use of social media [17].

Nevertheless it is not a panacea in other ways too: ROI is difficult to measure and may require different measures $[11,16,17,28]$ and social networking can be used against the organization $[2,15]$. The role of the product manager is changing, in that it is moving from control and promotion of the brand to facilitate sharing. If the expected package around the brand (download speeds, website experience and navigation, information about the product, delivery choices and performance are examples), does not eventuate, this can be a serious setback for the business [5].

The issues of customer generated content and collaboration can be considered against the social media Web 2.0 tools of blogs, social networks, content communities, and the opportunities offered by content aggregators [6]. This underlines the array of enabling technologies embedded in social networking and Web 2.0 enabling not only Internet retailing but the use of the Internet to promote retail opportunities and be used as a marketing tool.

Workplace productivity can be improved by social networking technology. Enhanced communications and the collaboration of employees aiding in knowledge transfer will allow organizations to become more agile. In an age where many employees use a form of telecommuting or work in different locations, social networking can provide enhanced levels of employee satisfaction by reducing the social isolation of teleworkers and making them feel part of organizational culture [1]

In the last year or two there have been two other significant technological developments that have had a significant impact on these issues. The first is cloud computing [9] providing an opportunity for most organizations have access to the computing technology needed in order to compete. The other is business intelligence, providing new insights into customer activities such as enabling companies to search past purchasing patterns to predict future purchases [8] - while it is possible this technology will assist all organizations, big business is probably best placed to exploit the opportunity and continue the developing focus on customer-centricity.

The above would indicate a number of opportunities, and risks, for small business. Noting the spread of social networks Turban et al 2011 [26] proffered a research framework to enable study of the opportunities that the Web 2.0 tools and social networks provided to organizations. These opportunities as noted by Turban et al are around the areas of information dissemination and sharing, communication, collaboration and innovation, training and learning, knowledge management activities and problem-solving. Arising out of a comprehensive examination of the existing literature they proposed a framework for research. Their proposed research framework (shown in figure 1 below) is adapted from the Tjan 2001[25] viability-fit model and takes into account the features of the technology as it matches the requirements of the task. In other words, for social networking to be useful it will need to be able to be applied to appropriate tasks - how can we use the technology to achieve the objectives of those tasks? The model suggests that "fit" is determined by task related activities and the use of available technology; "viability" is determined by economic decisions, the readiness of the organization to deal with what the technology offers from both technological and organizational standpoints. The fit and viability will determine decisions regarding deployment, which can be evaluated by performance. 


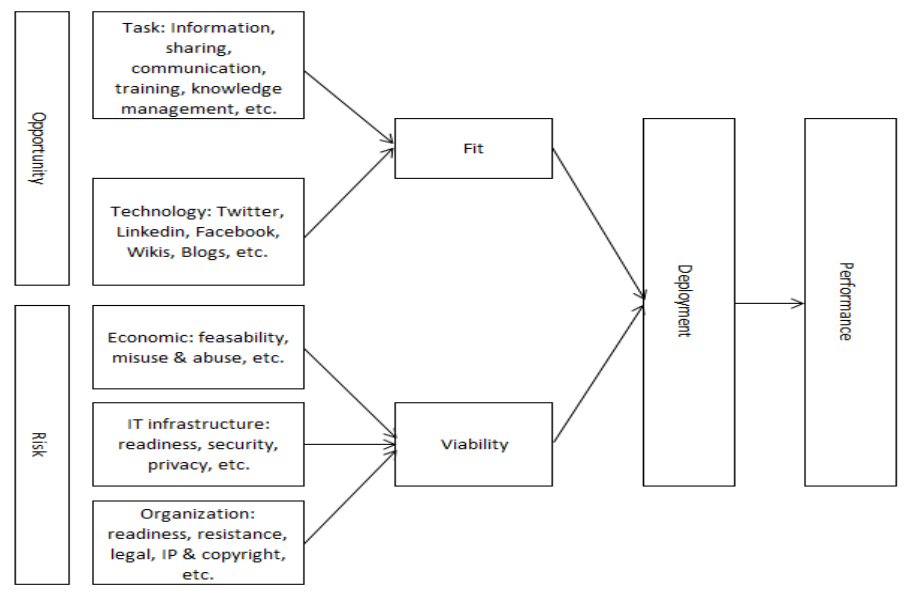

Figure 1:Proposed Research Model (Turban et al)

This study is an attempt to validate the research framework by testing it against the use of social networking by small business in the South East United States. Validation of the framework will allow a more substantial study and should highlight areas for modification. The outcome of this research should provide small business with some guidance as to "what works" and some indication of the pitfalls they may encounter.

The following research questions are proposed:

1. Can the (untested) framework proposed by Turban et al [26] be used as a research model to determine whether small businesses can take advantage of social networking to enhance their performance?

2. To what extent do the various factors related to tasks, technology, economics and organizational readiness influence the decision to deploy social networking and its ultimate performance?

Accordingly, and based on the Turban et al framework it is hypothesized that:

1. Tasks related to the opportunity factors of knowledge management, communication, sharing and training will have a positive influence on task fit

2. Technology will have a positive influence on task fit

3. The risk factors of organizational readiness, infrastructure and economics will have a positive influence on viability

4. Fit and viability will influence deployment

5. Deployment will influence performance

(Note that these are summarized into groups here, there are 11 in total, full details are given in the Conclusion)

\section{RESEARCH METHODOLOGY}

The measurement constructs were developed by researchers with considerable experience in scale construction and with the benefit of a previous exploratory study of social networking in small business and based upon scales used in the IS literature. The initial instruments were pretested for content and face validity by obtaining feedback from other scholars in the related field. In addition practitioners proficient in the field were asked to comment on the questionnaire as it related to structure, clarity, ambiguity, appropriateness \& completeness [20].

The exploratory study involved 25 small businesses each with less than 50 employees. The collection of data, achieved by using a research assistant to visit each of the small businesses, did not reveal major concerns as it related to the clarity of instructions, response formats, or survey length. All 25 questionnaires were completed by the research assistant in the presence of the business representative. Non-response bias is not considered to be an issue here as only a small number of businesses were unwilling to complete the survey due to work-pressure at the time. 


\section{Issues in Information Systems}

Volume 14, Issue 1, pp.234-243, 2013

Partial Least Squares (PLS) analysis was chosen as the primary analysis tool for testing the hypotheses. The PLS model is shown below in Figure 2.

PLS is a component based structural equation modeling technique which is an appropriate method when current research deals with emerging theory and/or sample size is limited [22]. In addition, PLS is a preferred method when the research is interested in the ability to predict endogenous variables $[3,13]$. In addition, PLS is robust regarding violations of multivariate normality, which are typical in small sample sizes [19]. However, the major determinant for selecting a component base structural equation model over a covariance one, lies in the ability of PLS to estimate more conservative path coefficients estimates [3,20]. All 12 latent constructs are composed of reflective indicators. The latent construct indicators were selected based on the IS literature, academic experience and practitioner feedback.

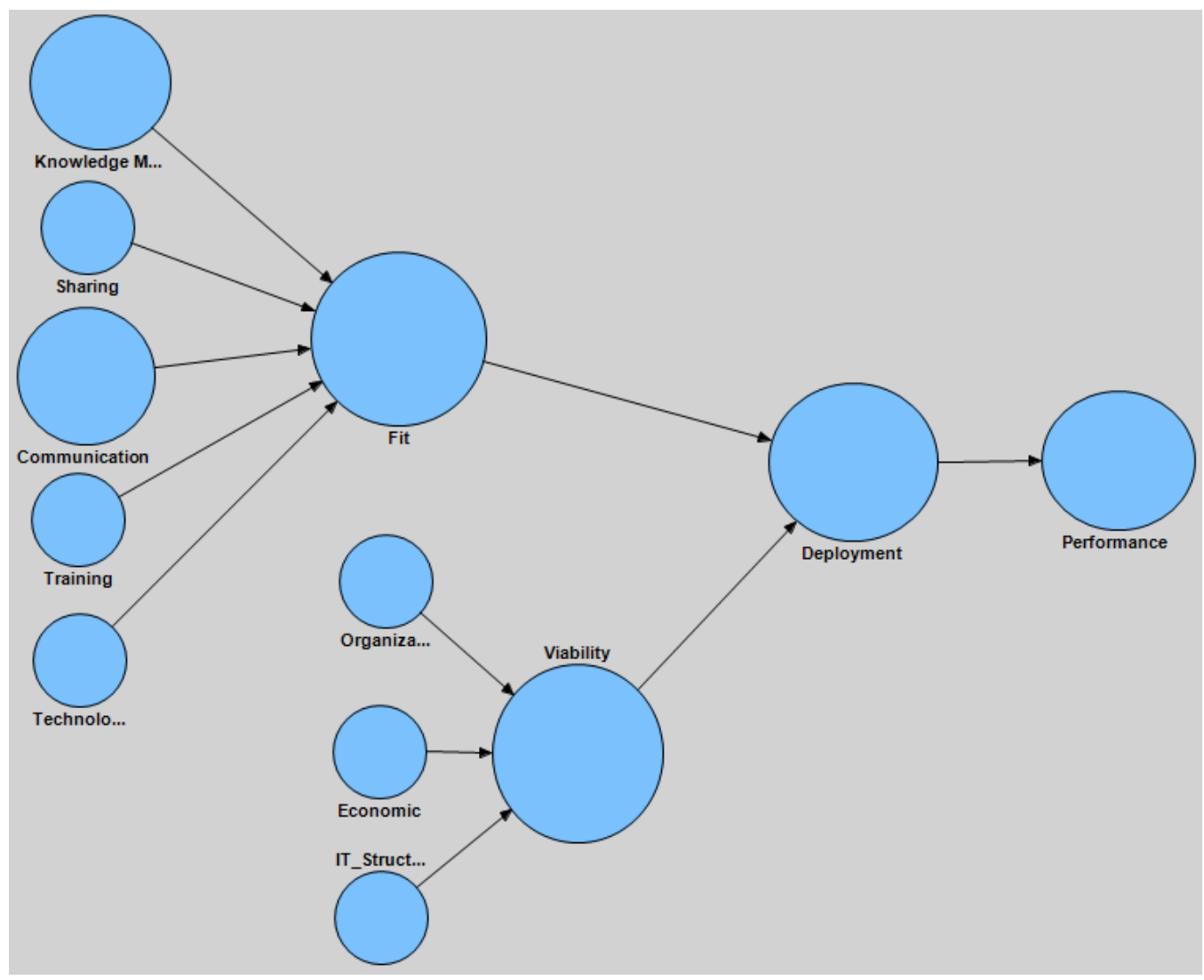

Figure 2: PLS Research Model

\section{RESULTS}

For this study the PLS guidelines prescribed by Peng \& Lai [19] and Hair et al. [13] were followed. SmartPLS 2.0.M3 was used to estimate our research model. The item loadings, composite reliability (CR), average variance extracted (AVE) and variance inflation index (VIF) of the reflective constructs are shown in Table 1. Five measurement items and three exogenous variables were dropped due to low loadings. All other loadings were above the .70 threshold (Hair et al. 2011). The complete model is shown in Appendix A. A $X^{2}$ difference test was also conducted which allows for a comparison between a general model where all paths are correlated and a nested model where a path is constrained. A significant result from the $X^{2}$ difference test indicates discriminant validity. The $X^{2}$ results indicate there is discriminant validity between Economic, Fit and Performance. 
Table 1: Overview of Reliability and Validity

\begin{tabular}{|c|c|c|}
\hline & \multicolumn{2}{|l|}{ Outer Loadings } \\
\hline & Point Estimation & $t$-Value \\
\hline \multicolumn{3}{|c|}{ Technology ( $\alpha=1, \mathrm{AVE}=1, \mathrm{CR}=1, \mathrm{VIF}=2.19$ ) } \\
\hline A12 & 1.000 & - \\
\hline \multicolumn{3}{|c|}{ Sharing ( $\alpha=.799$, AVE $=.703$, CR $=.876$, VIF $=1.72$ ) } \\
\hline B1 & 0.747 & 2.428 \\
\hline B5 & 0.864 & 4.048 \\
\hline B6 & 0.897 & 3.861 \\
\hline \multicolumn{3}{|c|}{ Knowledge_Management $(\alpha=.939$, AVE $=.942, \mathrm{CR}=.970, \mathrm{VIF}=2.64)$} \\
\hline B11 & 0.973 & 25.804 \\
\hline B12 & 0.968 & 13.418 \\
\hline \multicolumn{3}{|c|}{ Communication ( $\alpha=.587, \mathrm{AVE}=.705, \mathrm{CR}=.827, \mathrm{VIF}=1.57$ ) } \\
\hline B2 & 0.798 & 2.337 \\
\hline B7 & 0.880 & 3.061 \\
\hline B8 & & \\
\hline \multicolumn{3}{|c|}{ Training ( $\alpha=.767$, AVE $=.704, C R=.868$, VIF $=2.18$ ) } \\
\hline B3 & 0.9304 & 4.169 \\
\hline B9 & 0.8174 & 3.150 \\
\hline \multicolumn{3}{|c|}{ Economic $(\alpha=.823$, AVE $=.561$, CR $=.863$, VIF $=1.49$ ) } \\
\hline B16 & 0.836 & 5.351 \\
\hline B21 & 0.686 & 3.462 \\
\hline \multicolumn{3}{|c|}{ IT Structure $(\alpha=.668 \mathrm{AVE}=.492, \mathrm{CR}=.794, \mathrm{VIF}=1.67)$} \\
\hline B17 & 0.714 & 4.050 \\
\hline B24 & 0.717 & 2.044 \\
\hline B26 & 0.642 & 1.696 \\
\hline B27 & 0.727 & 4.364 \\
\hline \multicolumn{3}{|c|}{ Organizational Readiness $(\alpha=.674$, AVE $=.515, \mathrm{CR}=.806$, VIF $=1.30$ ) } \\
\hline B18 & 0.732 & 4.000 \\
\hline B19 & 0.785 & 4.176 \\
\hline B22 & 0.800 & 4.327 \\
\hline B25 & 0.519 & 1.820 \\
\hline
\end{tabular}

$\alpha$ - Cronbach's alpha; AVE - average variance explained; $C R=$ composite reliability

VIF - variance inflation factor

The bootstrapping procedure was employed to estimate errors and the significance of parameter estimates [4, 19]. A bootstrapping resample of 500 was utilized [4]. Results indicate that all reflective items had a significance level greater than .01. In addition, a VIF test was run to determine if multi-collinearity was present. All results were below 3.3, which indicate no multi-collinearity is present [7].

Construct reliability was assessed by Cronbach's alpha and Composite Reliability (CR). Cronbach's alpha was above .7 for all constructs except for Training. Nevertheless, all CR values were greater than .80 which is well above the suggested .60 when conducting exploratory studies (Hair et al 2011). Convergent validity was assessed by AVE. All AVE values were above the recommended value of .50 [10, 13].

Stone-Geisser $\mathrm{Q}^{2}$ was used to assess the predictive significance of the exogenous variables $[11,23]$. Blindfolding is the recommended technique for assessing $\mathrm{Q}^{2}$ when running a PLS model. The omission distance (D) parameter should range from 5 to 10 [27]. In this study an omission distance of 6 and a mean case replacement option were used to run the blindfolding procedure. All $\mathrm{Q}^{2}$ values were greater than zero indicating sufficient predictive power of the structural model exists [19]. 


\section{Issues in Information Systems}

Volume 14, Issue 1, pp.234-243, 2013

Pend and Lai [19] recommend testing the overall quality of the model by utilizing the goodness-of-fit proposed by Tenenhaus et al. [24]. Its calculation is as follows (it essentially takes into account measurement variability and variance explained) and provides some assurance around the model, even though sample size is small:

$$
\mathrm{GOF}=\sqrt{ }\left(\text { Average Communality } \times \text { Average } \mathrm{R}^{2}\right)=\sqrt{ }(.75 \times .53)=.63
$$

This omnibus test does incur some criticism by some scholars such as Hair et al (2011). One of the arguments against this test is the fact that $\mathrm{R}^{2}$ values depends on the research context. For example, if the research is exploratory, lower values of $\mathrm{R}^{2}$ are accepted; while this may not be the case for testing established theory. However, the average communality for the reflective models is above the threshold of .7 and the average $\mathrm{R}^{2}$ for the endogenous variables has a moderate value. So, .65 is a moderate value when considering the context of this exploratory study. The individual endogenous variable range from moderate to substantial based on the recommendations of Chin [3] and Peng \& Lai [19]. The variables with a moderate $\mathrm{R}^{2}$ are Fit (.586) Deployment (.437) and Viability (.438) while Performance (.657) had a substantial $\mathrm{R}^{2}$.

In order to test path stability bootstrapping was run with 200,500 and 1,000 times of resampling to assess the magnitude and significance path of the structure model are consistent [19]. Results from the 500-bootstrapping run can be found in Table 2. Additionally, the effect size $\left(\mathrm{f}^{2}\right)$ was calculated for each of the exogenous variables. The effect size provides the impact an exogenous variable has as it relates to the endogenous variable $\mathrm{R}^{2}$. This helps asses the substantive impact the exogenous variable has with respect to the endogenous [14]. Results indicate we have between small to large effect (see Table 3). The results indicate that four out of the eleven hypotheses are supported, of which $\mathrm{H} 9$ and $\mathrm{H} 11$ are significant at the .01 level, $\mathrm{H} 1$ is significant at the .05 while $\mathrm{H} 4$ is significant at the .10 level.

Table 2: Path Coefficients and R-squared values

Path coefficients and $R^{2}$ of structural model

\begin{tabular}{|c|c|c|c|c|c|c|}
\hline \multirow[t]{2}{*}{ Constructs and indicators } & \multicolumn{2}{|c|}{ Path coefficient } & \multirow{2}{*}{\multicolumn{2}{|c|}{ Hypothesis }} & \multirow[b]{2}{*}{ Cohen $f^{2}$} & \multirow[b]{2}{*}{$Q^{2}$} \\
\hline & Point estimate & $t$-Value & & & & \\
\hline Fit $\left(R^{2}=.586\right) R^{2}$ & & & & & & 0.321 \\
\hline Knowledge Management & 0.385 & 2.509 & $\mathrm{H} 1$ & Supported & 0.27 & \\
\hline Communication & 0.376 & 1.386 & $\mathrm{H} 2$ & Rejected & 0.18 & \\
\hline Sharing & $(0.316)$ & 0.941 & H3 & Rejected & 0.06 & \\
\hline Technology & $(0.666)$ & 1.775 & $\mathrm{H} 4$ & Supported* & 0.43 & \\
\hline Training & $(0.188)$ & 0.535 & H5 & Rejected & 0.03 & \\
\hline Viability $\left(R^{2}=.438\right) R^{2}$ & & & & & & 0.328 \\
\hline Organization_Readines & 0.237 & 0.905 & $\mathrm{H} 6$ & Rejected & 0.03 & \\
\hline IT_Structure & 0.330 & 0.941 & H7 & Rejected & 0.10 & \\
\hline Economic & 0.197 & 0.612 & H8 & Rejected & 0.05 & \\
\hline Deployment $\left(R^{2}=.437\right)$ & & & & & & 0.351 \\
\hline Fit & 0.526 & 2.611 & H9 & Supported & 0.32 & \\
\hline Viability & 0.196 & 0.905 & $\mathrm{H} 10$ & Rejected & 0.05 & \\
\hline Performance $\left(R^{2}=.657\right)$ & & & & & & 0.391 \\
\hline Deployment & 0.811 & 15.693 & $\mathrm{H} 11$ & Supported & & \\
\hline
\end{tabular}

* Supported at significance of $P<.10$ 


\section{Issues in Information Systems}

Volume 14, Issue 1, pp.234-243, 2013

Table 3 : Effect size and Predictive Relevance

\begin{tabular}{|c|c|c|c|}
\hline & & Cohen $f^{2}$ & $Q^{2}$ \\
\hline \multirow[t]{6}{*}{ Fit } & & & 0.321 \\
\hline & Knowledge Management & 0.27 & \\
\hline & Communication & 0.18 & \\
\hline & Sharing & 0.06 & \\
\hline & Technology & 0.43 & \\
\hline & Training & 0.03 & \\
\hline \multirow[t]{4}{*}{ Viability } & & & 0.328 \\
\hline & Organization_Readines & 0.03 & \\
\hline & IT_Structure & 0.10 & \\
\hline & Economic & 0.05 & \\
\hline \multicolumn{2}{|c|}{ Deployment } & & 0.351 \\
\hline & Fit & 0.32 & \\
\hline & Viability & 0.05 & \\
\hline \multicolumn{2}{|c|}{ Performance } & & 0.391 \\
\hline & Deployment & & - \\
\hline
\end{tabular}

\section{CONCLUSIONS}

The study to date has clear limitations - first the sample size is small and in many cases at the borderline where meaningful statistical analysis can be conducted. Secondly, the model goodness of fit statistic is marginal, so only limited confidence can be place in its predictive value at this point. Technology was measured by the relatively crude method of a count of the number of types of social media in use - further work in this is clearly needed. Nevertheless, in essence the authors believe the structural equation modeling analysis employed to evaluate the framework gives it considerable support, especially given the small sample size. A revised model showing the significant is shown in Figure 3.

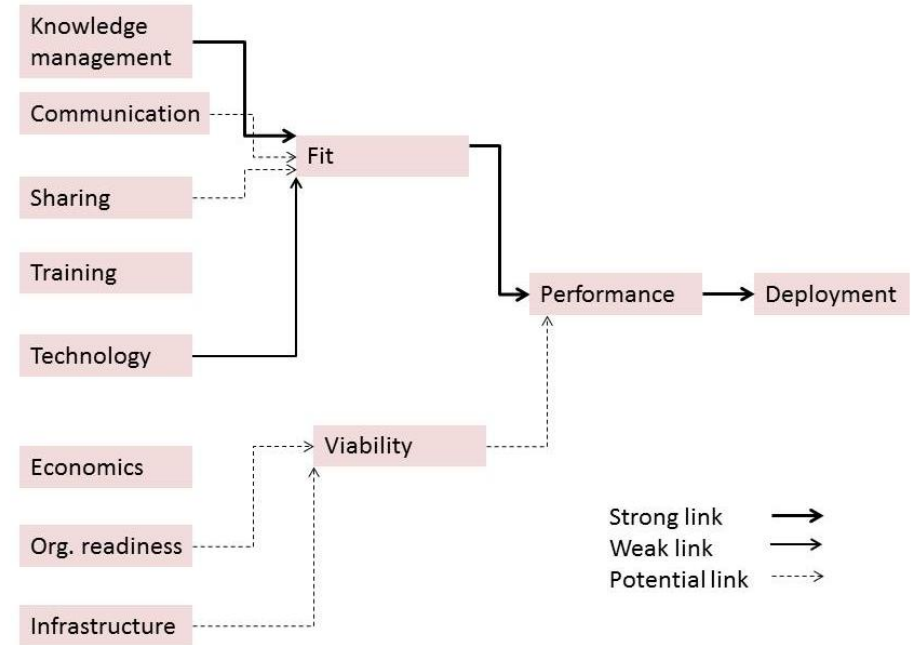

Figure 3: Revised Model 


\section{Issues in Information Systems}

Volume 14, Issue 1, pp.234-243, 2013

The authors are encouraged to continue this research with a larger data set and expect to see stronger path coefficients and predictive ability, suggesting the framework developed by Turban et al [26] has significance and implications for small business use of social networking. As such the data is expected to contribute to theory by validating the model and providing a sound framework for further more applied research.

The paper has also demonstrated the usefulness of Structural Equation Modeling in analysis of small data sets and in exploratory research. The authors hope that the methodology employed here will provide a useful guide for similar data sets requiring analysis. PLS-SEM is a recommended method when a theory is under development such as the study conducted here [13]. This study has employed the practices put forth by Hair et al. [14], Peng \& Lai [19], and Vinzi et al, (2010).

The findings, with implications for practice, suggest that the knowledge management tasks of providing information about the business and products on offer, and technology are driving the fit of social networking to the enterprise and that the degree of fit is the predominant force in the decision to deploy which is validated by performance. There is also some indication in the model that communication and sharing of information with customers may affect fit and that the viability in terms of infrastructure and organizational readiness may also influence the decision to deploy. These results suggest that small business owners and managers who feel that their organizations are ready to embrace the technology and have the infrastructure in place will benefit from engaging stakeholders in the areas of providing information with them, be they staff, customers or suppliers. In turn this may provide small business with a way to compete more effectively with larger organizations by enabling them to exploit the data and technology in a similar way and use it to enhance the strategic advantage small business - a focus on customercentricity.

\section{REFERENCES}

1. Bennett, K., Pitt M. and. Owers, M. (2010) Workplace Impact of Social Networking Liverpool Conference on the Built Environment and natural Environment 60-72

2. Berhoff, J and Li, C. (2008) Harnessing he Power of the OH-So-Social Web Sloan Management Review 49 (3), 36-42

3. Chin, W. (1998a). Commentary: Issues and opinion on structural equation modeling. MIS Quarterly, viixvi.

4. Chin, W. (1998b). The partial least squares approach for structural equation modeling. In: Marcoulides, G.A (Ed.), Modern Methods for Business Research. Lawrence Bribaum Associates, Mahwah, NJ, pp 295336.

5. Christodoulides, G. (2009) Branding in the post-internet era Marketing Theory online Available: http://mtq.sagepub.com/cgi/content/abstract/9/1/141

6. Constantinides, E., Romero, C. L. and Gomez Boria, M. A. (2008) Social Media: A new Frontier for Retailers? European Retail Research 22, 1-28

7. Diamantopoulos, A., and Siguaw, J. A. (2006). Formative Versus Reflective Indicators in Organizational Measure Development: A Comparison and Empirical Illustration. British Journal of Management, 17(4), 263-282.

8. Duhigg, C. (2012) How Companies Learn Your Secrets New York Times February 16, online Available: http://www.nytimes.com/2012/02/19/magazine/shopping-habits.html?pagewanted=all\&_r=0

9. Erickson, J. S., Spence, S., Rhodes, M., Banks, D., Rutherford, J., Simpson, E., Belrose, G. and Perry, R. (2009) Content-Centered Collaboration Spaces in the Cloud IEEE Internet Computing Sept/Oct 34-42

10. Fornell, C., \& Larcker, D. F. (1981). Evaluating structural equation models with unobservable variables and measurement error. Journal of Marketing Research, Vol XVIII 39-50.

11. Geisser, S. (1975). The Predictive Sample Reuse Method with Applications. Journal of the American Statistical Association, 70 (350), 320-328.

12. Gneiser, M., Heidemann, M. K. and Landherr, F.P. (2012) Valuation of Online Social Networks Taking into Account Users' Interconnectedness. Information Systems and e-Business Management 10 (1), 61-84 
13. Hair, J. F., Sarstedt, M., Ringle, C. M., \& Mena, J. A. (2011). An assessment of the use of partial least squares structural equation modeling in marketing research. Journal of the Academy of Marketing Science, 40(3), 414-433.

14. Hair, J. F., Hult, G. T. M., Ringle, C. M., \& Sarstedt, M. (2013). A Primer on Partial Least Squares Structural Equations Modeling (PLS-SEM). SAGE Publications.

15. Hills, J. R. and Cairncross, G. (2011) Small accommodation providers and UGC web sites: perceptions and practices. International Journal of Contemporary Hospitality Management 23 (1), 26-43

16. Hoffman, D. L. and Fodor, M. (2010) Can you Measure the ROI of Your Social Media Marketing? Sloan Management Review 52 (1), 41-49

17. Larson, K and Watson, R (2011) The Value of Social media: Toward Measuring Social Media Strategies. Proceedings of the Thirty Second International Conference on Information Systems, Shanghai

18. Liang, T. P., Huang, C. W., Yeh, T. H. and Lin B. (2007) Adoption of mobile technology in business: A fitviability model Industrial management and Data Systems 107(8), 1154-1169

19. Peng, D. X., \& Lai, F. (2012). Using partial least squares in operations management research: A practical guideline and summary of past research. Journal of Operations Management, 30(6), 467-480.

20. Rexhausen, D., Pibernik, R., \& Kaiser, G. (2012). Customer-facing supply chain practices-The impact of demand and distribution management on supply chain success. Journal of Operations Management, 30(4), 269-281.

21. Sinclaire, J. K. and Vogus, C.E. (2011) Adoption of social networking sites: an exploratory adaptive structuration perspective for global organizations Information Technology and Management 12 (4) 294 314

22. Sosik, J. J., Kahai, S. S., \& Piovoso, M. J. (2009). Silver Bullet or Voodoo Statistics?: A Primer for Using the Partial Least Squares Data Analytic Technique in Group and Organization Research. Group \& Organization Management, 34(1), 5-36.

23. Stone, M. (1974). Cross-validatory choice and assessment of statistical predictions. Journal of the Royal Statistical Society. Series B (Methodological), 111-147.

24. Tenenhaus, M., Vinzi, V. E., Chatelin, Y.-M., \& Lauro, C. (2005). PLS path modeling. Computational Statistics \& Data Analysis, 48(1), 159-205.

25. Tjan, A. K. (2001) Finally, a way to put your Internet Portfolio in Order Harvard Business Review 79 (2) 76-85

26. Turban, E., Bolloju, N. and Liang, T. P. (2011) Enterprise Social Networking: opportunities Adoption and Risk Mitigation Journal of Organizational Computing and Electronic Commerce 21, 202-220

27. Vinzi, V. E., Chin, W. W., Henseler, J., \& Wang, H. (Eds.). (2010). Handbook of Partial Least Squares: Concepts, Methods and Applications (2010 ed.). Springer.

28. Weinberg, B. D. and Pehlivan, E. (2011) Social spending: Managing the social media mix. Business Horizons 54, 275-282 


\section{Appendix A}

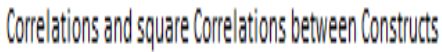

\begin{tabular}{|c|c|c|c|c|c|c|c|c|c|c|c|c|}
\hline & \multicolumn{12}{|c|}{ Krowlelgere Organinizition } \\
\hline & Comminiation & Deplopinertit & Economic & fit & II Stuturue & Malsgegnentit & Rexhlines & Pethomille & Shallig & Tethrology & Irailing & Viablity \\
\hline Communination & 0,015 & 0.154 & 0.053 & 0.12 & 0005 & 0.005 & 0.005 & 0.28 & 0.49 & 0.155 & 0.212 & 0.036 \\
\hline Deploynelt & 0.322 & 0.900 & 0.54 & 0.11 & 0.101 & 0.53 & 0.332 & 0657 & 0.316 & 0.98 & 0.19 & 0.266 \\
\hline Emovonic & 0.30 & 0.378 & $0,561$. & 0.675 & 0.48 & 0.522 & 0.973 & 0.607 & 0.145 & 0.400 & 0.149 & 0.35 \\
\hline Fit & 0.49 & 0.64 & 0.821 & 0.987 & 0.111 & 0,306 & 0.232 & 0.64 & 0.14 & 0.49 & 0.116 & 0.348 \\
\hline II Stuture & (0.0689) & 0.318 & 0.639 & 0.400 & and & 0.43 & 0.313 & 0.24 & 0.031 & 0.189 & 0.008 & 0.346 \\
\hline Knowlelge Malobegenentit & 0.072 & 0.673 & 0.724 & 0.53 & 0.38 & 0.942 & 0.268 & 0.283 & 0.081 & 0.199 & 0.124 & 0028 \\
\hline Opgandintiton Redidnes & $(0.072)$ & 0.56 & 0.687 & 0.81. & 0560 & 0.518 & 0.515 & 0.664 & 0.011 & 0.142 & 0.001 & 0.30 \\
\hline Pertommblue & 058 & 0811. & 0.79 & 0.796 & 0.74 & 0.513 & 0.514 & 0,667 & 0.939 & 0.53 & 0.32 & 0.569 \\
\hline Shaling & 0.670 & 0562 & 0.381. & 0.39 & 0.175 & 0.284 & 0103 & 0627 & 0,70 & 0.518 & 0.002 & 0.130 \\
\hline Tethology & [0.3931) & (0.668) & (0.678) & |0.639| & $\mid 0,424)$ & (0.47) & (0.37) & |0.079 & $(0720)$ & 1.000 & D.MA & 0200 \\
\hline Tràning & 0.567 & 0.699 & 0.386 & 0.340 & 0088 & 0.352 & 0027 & 056 & 0.776 & $\mid 0.6560$ & 0,667 & ONA2 \\
\hline Viability & 0.189 & 0.56 & 0.57 & 0.50 & 0988 & 0.69 & 0.557 & 0.759 & 0.361 & $(0.47)$ & 0.206 & 0,778 \\
\hline
\end{tabular}

